\title{
Misdiagnosed Hypomanic Symptoms in Patients with Treatment-Resistant Major Depressive Disorder in Italy: Results from the Improve Study
}

\author{
Moro Maria Francesca ${ }^{1}$, Lecca Maria Efisia ${ }^{1}$, Ghillani M. Alessandra ${ }^{2}$, Alacqua Marianna ${ }^{2}$ and \\ Carta Mauro Giovanni, ${ }^{1, *}$
}

\author{
${ }^{1}$ Division of Psychiatry, Department of Public Health, University of Cagliari, Italy; \\ ${ }^{2}$ Medical Department, AstraZeneca Italy $S p A$
}

\begin{abstract}
Background: Undiagnosed and therefore inadequately treated hypomanic symptoms may be a leading cause of drug resistance in depression diagnosed as unipolar (major depressive disorder, MDD). The purpose of the IMPROVE study was to identify the rate of misdiagnoses in patients with treatment-resistant MDD by screening for the presence of previous hypomanic episodes, and to study the characteristics of those patients with a positive history of hypomania. Methods: Patients attending 29 psychiatric units throughout Italy with a diagnosis of MDD who were resistant to antidepressant treatment were included in this multicentre, observational single visit study. The Hypomania Checklist 32 (HCL-32) was administered to detect underlying bipolarity. Results: Among the 466 enrolled patients, 256 (57.40\%) were positive at screening for a previous hypomanic episode (HCL-32 $\geq 12$ ), therefore suggesting a misdiagnosis. These patients scored higher than those with a negative history in both the "active/elated hypomania" (11.27 $\pm 3.11 \mathrm{vs} 3.57 \pm 3.05$; $\mathrm{P}<0.0001)$ and "irritable/risk-taking hypomania" $(2.87 \pm 2.03$ vs $2.06 \pm 1.73 ; \mathrm{P}<0.001)$ HCL-32 sub-scales. Patients with a positive history of hypomania were younger, had a higher number of previous depressive episodes and a higher frequency of comorbid conditions compared to those with a negative history. Conclusions: This study suggests that screening for hypomania in MDD-resistant patients facilitates identification of a notable proportion of undiagnosed cases of bipolar spectrum disorder. Patients with a positive history of hypomania at screening had a demographic/clinical bipolar-like profile that included young age, higher number of previous depressive episodes and higher frequency of comorbid conditions. They also had both higher active and irritable hypomania symptom scores.
\end{abstract}

Keywords: Active hypomania, bipolar symptoms, HCL-32, irritable hypomania, resistant MDD, screening.

\section{INTRODUCTION}

Major depressive disorder (MDD) is a common chronic condition with a lifetime prevalence of around $13-17 \%$ in Europe and the USA [1-5]. MDD is the source of a substantial economic burden for both sufferers and society: in 1990 the treatment-related costs (direct costs) in the USA were estimated to be approximately US\$ 19.9 billion, whereas the indirect costs were US\$ 57.5 billion [4] for a total of US\$ 77.4 billion, which rose to US\$ 83.1 billion in 2000 (inflation-adjusted US dollars) [6]. In parallel, from 1990 to 2010 , MDD increased from the 15 th to 11 th rank $(37 \%$ increase) among the leading causes of disability worldwide [7].

Although several treatments have been found to be effective in the management of depressive episodes and patients may benefit from several classes of first-line antidepressant drugs, resistance to treatment is a major concern [3]. According to the STAR*D study, only $32.9 \%$ of patients achieved remission with first choice of antidepressant therapy, which was represented by selective serotonin reuptake inhibitors (SSRI) [8].

*Address correspondence to this author at the Center of Liaison Psychiatry and Psychosomatics, University Hospital, Via Ospedale 117, 09123 Cagliari, Italy; Tel: +39 335 499994; E-mail:mgcarta@tiscali.it
Treatment-resistant depression is defined as no response to at least two antidepressants from different pharmacological classes given at adequate doses for a sufficient duration [9-11].

One possible major determinant of resistance to antidepressants in diagnosed MDD is the misdiagnosis of bipolar disorder among patients with chronic depressive episodes [12].

Many patients with bipolar disorder remain undetected or are initially misdiagnosed as having unipolar depression $[13,14]$. An important reason for this misdiagnosis is that depressed patients do not talk to their care provider spontaneously about their previous hypomanic symptoms [15]. A misdiagnosis of unipolar depression for bipolar depression can lead to inappropriate treatment, such as antidepressant monotherapy [16] which, in the absence of mood stabilisers, may be ineffective against depressive symptoms and lead to induction of chronicity, manic switching, mixed symptoms and rapid cycling [16, 17]. Furthermore, it has been suggested that treatment-resistant MDD increases medical costs and could be due to a missed underlying bipolar disorder $[3,12]$.

In a recent study, Dudek et al. compared patients with treatment-resistant MDD with those who had treatmentresponsive MDD using the Hypomania/Mania Symptom 
Checklist (HCL-32) as a tool to assess the presence of hypomanic symptoms [12]. They found that the proportion of patients with bipolarity features, detected by HCL-32, was significantly higher among patients with treatment-resistant MDD than among patients who responded to treatment [12].

The purpose of the IMPROVE study was to identify potential misdiagnoses among patients with treatment-resistant MDD in Italy by screening for the presence of previous hypomanic episodes. Factors associated with a hypomanic status were also investigated.

\section{METHODS}

\section{Design}

This was a multicentre, observational, single-visit study. (clinical trial.gov NCT01344733)

\section{Objectives}

The primary objective was to detect underlying bipolarity in patients with treatment-resistant MDD. Secondary objectives were to identify determinants of misdiagnosis, including demographics, medical history, clinical/symptomatic profile and medications.

\section{Study Tools}

The HCL-32, an instrument developed by Angst et al. and translated in several languages, is a simple, selfadministered, 32-item questionnaire. The scale can provide important insights into unrecognised hypomanic symptoms $[18,19]$. In an Italian validation study, a positive answer to at least 12 items was found to be the best cut-off for detecting a hypomanic condition [18].

\section{Study Sample}

All treatment-resistant MDD patients aged between 18 and 65 years consecutively evaluated in 29 Italian centres were included in the study. The planned enrolment period was from May 2011 to March 2012.

The diagnosis of treatment-resistant MDD was made according to DSM-IV TR (296.3 x); with treatment resistance defined as non-response to at least two antidepressants given at adequate doses for a sufficient period, with the last antidepressant treatment on-going. In accordance with the primary study objective, the estimation of sample size was based on the expected HCL-32 score in treatment-resistant patients in previous studies $[10,16]$. Assuming 5\% first type error and a power of $90 \%$ and conducting a two-tailed t-test, a total of 660 patients was sufficient for detecting as statistically significant an absolute difference in the HCL-32 score of 2.1 between the group of patients treatment resistant due to other causes and the group of patients treatment resistant due to bipolarity (expected 11.9 \pm 8.3 ).

From the first 202 patients enrolled in our study, it was noted that the proportion of HCL-32-positive subjects enrolled was greater than expected, namely $58.29 \%$. The number of patients enrolled by the 29th February 2012 was sufficient for to detect a statistically significant absolute difference in the HCL-32 score of 2.1 with an $\alpha=0.05$ and a power of almost $90 \%$. For this reason, on the 14th March 2012 en- rolment was prematurely closed with a total cohort of 446 patients enrolled.

\section{Treatments}

Neither the efficacy nor the tolerability of pharmacological treatments was assessed. However, information on antidepressant treatments and concomitant medications was collected for descriptive purposes. All subjects enrolled completed the HCL-32.

\section{Statistical Analysis}

Patients were divided into two groups according to the total HCL-32 score: a group with hypomanic symptoms (score $\geq 12$ ) and a group without hypomanic symptoms $($ score $<12)$. All the recorded data and derived variables were summarized by means of descriptive statistics.

The primary efficacy analysis was performed on patients without missing data in the 32 items of the scale used. The total score (complete case population) on the HCL-32 was computed as the sum of positive answers to the 32 items of the questionnaire.

The difference between the means in the two groups was estimated with a $95 \%$ confidence interval. A two-tailed t-test was also applied, to prove the hypothesis of a statistically significant difference between the two groups, with a $5 \%$ significance level. Two sub-scores addressing specific variants of hypomanic behaviour were also computed: "active/elated hypomania" and "irritable/risk-taking hypomania" sub-score.

A description of the demograpfics and anamnestic sample characteristics was provided. An explorative multivariate analysis was performed in order to investigate the effect of explicative factors (i.e. age, gender, family status, professional status, time elapsed from the onset of the current episode, number of previous episodes in the last year, relevant disease/pathology that could interfere with this pathology/treatment and treatment switch) on hypomanic condition status, identified by HCL-32 questionnaire. A logistic regression model including all the aforementioned variables was applied.

All the statistical analyses were performed using SAS System software, version 9.2.

\section{Ethics}

Informed consent to participation in the study was obtained from each subject. Patients unable to understand the meaning of the HCL-32 items were excluded.

Data were not nominal at source, and each subject was identified by a numerical code. The study was approved by the ethics committee of the University Hospital of Cagliari, Italy and by the local ethics committees of each collaborating centre. The research was conducted in compliance with the Helsinki Declaration.

\section{RESULTS}

\section{Demographics and Baseline Characteristics}

The study included 446 patients: 256 were positive at the screening (HCL-32 $\geq 12$ ) and formed the hypomanic group, 
while 185 were negative $(\mathrm{HCL}-32 \leq 11)$ and constituted the non-hypomanic group. Only five patients $(1.12 \%)$ had missing data making it impossible to allocate them to a group, thus the final study sample consisted of $441(98.88 \%)$ subjects. As had already emerged during an interim analysis, the proportion of HCL-32-positive subjects was confirmed to be greater than expected ( $43.9 \%$ of the subjects examined).

The mean age ( \pm standard deviation) was in the hypomanic group was statistically significantly lower than in the non-hypomanic group $(47.66 \pm 10.41$ years vs. $49.84 \pm 10.67$ years, respectively; $P=0.0196$ ) (Table 1). Females were more prevalent in the overall population (female $\mathrm{n}=305$, $68.39 \%$, male $n=141,31.61 \%$ ), although no intergroup difference in gender was noted.

The most represented work-status categories were 'Employed' (32.06\%), 'Homemaker' (30.94\%), 'Unemployed' (17.49\%) and 'Retired' (10.54\%). The distribution was not homogeneous between hypomanic and nonhypomanic groups, with the proportion of employed or selfemployed patients being higher in the hypomanic group and the proportion of homemakers being higher in the non- hypomanic group $(P=0.0216)$ (Table $\mathbf{1})$.

Table 1. Demographics of the patients divided according to their HCL-32 score.

\begin{tabular}{|l|l|l|}
\hline Characteristics & $\begin{array}{l}\text { Hypomanic } \\
\text { Group N=256 }\end{array}$ & $\begin{array}{l}\text { Non-Hypomanic } \\
\text { Group N=185 }\end{array}$ \\
\hline \hline Age, mean (SD), years & $47.66(10.41)$ & $49.84(10.67)$ \\
\hline Gender, N (\%) & & \\
\hline \multicolumn{1}{|c|}{ Male } & $80(31.25)$ & $59(31.89)$ \\
\hline \multicolumn{1}{|c|}{ Female } & $176(68.75)$ & $126(68.11)$ \\
\hline Family status, N (\%) & & \\
\hline Never married & $62(24.22)$ & $39(21.08)$ \\
\hline Married & $151(58.98)$ & $110(59.46)$ \\
\hline Separated & $23(8.98)$ & $14(7.57)$ \\
\hline Divorced & $10(3.91)$ & $13(7.03)$ \\
\hline Widowed & $10(3.91)$ & $9(4.86)$ \\
\hline Occupational status, N (\%) & & $12(6.49)$ \\
\hline Employed or self-employed & $93(36.33)$ & $50(27.03)$ \\
\hline Unemployed & $45(17.58)$ & $32(17.30)$ \\
\hline Homemaker & $71(27.73)$ & $64(34.59)$ \\
\hline Retired & $22(8.59)$ & $25(13.51)$ \\
\hline Student & $10(3.91)$ & $1(0.54)$ \\
\hline Sick leave & $8(3.13)$ & $7(2.73)$ \\
\hline Maternity leave or disability & & \\
\hline pension & & \\
\hline
\end{tabular}

\section{Clinical History and Medications}

In the overall population, patients had a mean of $3.58 \pm 13.50$ depressive episodes in the year prior to the study evaluation. The mean number of prior depressive episodes was higher in the hypomanic group than in the nonhypomanic group $(P=0.0245)$. At least one relevant concomitant disorder was recorded for 97 patients $(21.75 \%)$ in the overall population and this finding was more prevalent in the hypomanic group than in the non-hypomanic group $(\mathrm{n}=66 ; 25.78 \%$ vs. $\mathrm{n}=31 ; 16.76 \% ; P=0.0240)$.

The most frequently reported diseases among enrolled patients were hypertension, hypothyroidism and diabetes mellitus. Hypertension was present in 25 patients (5.61\%), of whom $17(6.64 \%)$ were in the hypomanic group and 8 $(4.32 \%)$ in the non-hypomanic group; hypothyroidism was present in 13 patients $(2.91 \%), 8(3.13 \%)$ in the hypomanic group and $5(2.70 \%)$ in the non- hypomanic group; and diabetes mellitus was present in 10 patients $(2.24 \%)$, of whom 6 $(2.34 \%)$ were in the hypomanic group and $4(2.16 \%)$ in the non-hypomanic group.

Almost all patients in both groups reported the prior and current use of medications $(97.98 \%$ and $99.33 \%$, respectively) and almost $80 \%$ of patients had a change in therapy in the preceding year, with no significant difference between the two groups.

\section{Primary End-Point}

Overall, 420 patients $(94.17 \%)$ completed the 32 -item HCL-32 questionnaire; $242(57.62 \%)$ of these 420 were in the hypomanic group. Among these 420 patients for whom complete information was available, the mean total HCL-32 score was $12.95 \pm 6.23$; in particular, in the hypomanic group the mean was $17.34 \pm 3.87$, while in the non-hypomanic group the mean total score was $6.99 \pm 3.05$; (mean difference 10.35, 95\% CI 9.69-11.01). Thus, hypomanic patients had a significantly higher total HCL-32 score than the patients without hypomania $(P<0.0001)$. These data are summarised in (Table 2).

The analysis of the HCL-32 sub-scores "active/elated hypomania" and "irritable/risk-taking hypomania" showed marked differences between the two groups. The scores for active/elated hypomania were $11.27 \pm 3.11$ in the hypomanic group and $3.57 \pm 3.05$ in the non-hypomanic group $(P<0.0001)$. A statistically significant difference was also noted for the irritable/risk-taking hypomania score, which was $2.87 \pm 2.03$ in the hypomanic group and $2.06 \pm 1.73$ in the non-hypomanic group $(P<0.0001)$. The items of the HCL-32 found to be more frequent in the hypomanic group than in the non-hypomanic group were inclinations to being more sociable ( $80.58 \%$ vs. $26.40 \%$, respectively; $P<0.0001$ ), being more talkative $(82.64 \%$ vs. $29.78 \%$; $P<0.0001)$, meeting more people ( $71.90 \%$ vs. $19.10 \%$; $P<0.0001)$, being physically more active $(69.83 \%$ vs. $17.42 \% ; P<0.0001)$, being more creative $(76.86 \%$ vs. $24.72 \% ; P<0.0001)$, making more jokes or puns $(64.88 \%$ vs. $12.92 \% ; P<0.0001)$, and doing things more quickly/easily ( $67.36 \%$ vs. $16.29 \% ; P<0.0001)$.

In the hypomanic group more numerically "high" episodes were recorded than in the non-hypomanic group: $2.61 \pm 5.80$ vs. $1.97 \pm 3.99$ episodes in the preceding 12 months 
Table 2. Total HCL-32 score and subscales scores: descriptive statistics.

\begin{tabular}{|c|c|c|c|}
\hline & $\begin{array}{l}\text { Total Sample } \\
\qquad \mathbf{N}=420\end{array}$ & $\begin{array}{l}\text { Hypomanic Group } \\
\qquad \mathrm{N}=\mathbf{2 4 2}\end{array}$ & $\begin{array}{c}\text { Non-Hypomanic Group } \\
\qquad N=178\end{array}$ \\
\hline \multicolumn{4}{|l|}{ Total HCL-32 score } \\
\hline Mean & 12.95 & 17.34 & 6.99 \\
\hline Standard deviation & 6.23 & 3.87 & 3.05 \\
\hline \multicolumn{4}{|l|}{ Active/Elated Hypomania Score } \\
\hline Mean & 8.01 & 11.27 & 3.57 \\
\hline Standard deviation & 4.90 & 3.11 & 3.05 \\
\hline \multicolumn{4}{|l|}{ Irritable/Risk-Taking Hypomania Score } \\
\hline Mean & 2.53 & 2.87 & 2.06 \\
\hline Standard deviation & 1.95 & 2.03 & 1.73 \\
\hline \multicolumn{4}{|l|}{ HCL-32 individual items, N (\%) } \\
\hline Item 1: Need less sleep & $135(32.14)$ & $103(42.56)$ & $32(17.98)$ \\
\hline Item 2: More energetic and active & $257(61.19)$ & $199(82.23)$ & $58(32.58)$ \\
\hline Item 3: More self-confident & $264(62.86)$ & $202(83.47)$ & $62(34.83)$ \\
\hline Item 4: Enjoy the work more & $225(53.57)$ & $179(73.97)$ & $46(25.84)$ \\
\hline Item 5: More sociable & $242(57.62)$ & $195(80.58)$ & $47(26.40)$ \\
\hline Item 6: Want and/or do travel more & $154(36.67)$ & $135(55.79)$ & $19(10.67)$ \\
\hline Item 7: Drive faster & $58(13.81)$ & $46(19.01)$ & $12(6.74)$ \\
\hline Item 8: Spend too much money & $90(21.43)$ & $80(33.06)$ & $10(5.62)$ \\
\hline Item 9: More risks in daily life & $75(17.86)$ & $62(25.62)$ & $13(7.30)$ \\
\hline Item 10: Phisically more active & $200(47.62)$ & $169(69.83)$ & $31(17.42)$ \\
\hline Item 11: Plan more activities or projects & $222(52.86)$ & $177(73.14)$ & $45(25.28)$ \\
\hline Item 12: More creative & $230(54.76)$ & $186(76.86)$ & $44(24.72)$ \\
\hline Item 13: Less shy & $227(54.05)$ & $172(71.07)$ & $55(30.90)$ \\
\hline Item 14: More colorful clothes/make-up & $96(22.86)$ & $90(37.19)$ & $6(3.37)$ \\
\hline Item 15: Meet more people & $208(49.52)$ & $174(71.90)$ & $34(19.10)$ \\
\hline Item 16: More interested in sex/sexual desire & $168(40.00)$ & $144(59.50)$ & $24(13.48)$ \\
\hline Item 17: More flirtatious and/or sexually active & $113(26.90)$ & $107(44.21)$ & $6(3.37)$ \\
\hline Item 18: Talk more & $253(60.24)$ & $200(82.64)$ & $53(29.78)$ \\
\hline Item 19: Think faster & $226(53.81)$ & $173(71.49)$ & $53(29.78)$ \\
\hline Item 20: More jokes or puns & $180(42.86)$ & $157(64.88)$ & $23(12.92)$ \\
\hline Item 21: More easily distracted & $203(48.33)$ & $125(51.65)$ & $78(43.82)$ \\
\hline Item 22: Engaged in new things & $112(26.67)$ & $106(43.80)$ & $6(3.37)$ \\
\hline Item 23: Thoughts jumping from topic to topic & $175(41.67)$ & $108(44.63)$ & $67(37.64)$ \\
\hline Item 24: Do things more quickly/easy & $192(45.71)$ & $163(67.36)$ & $29(16.29)$ \\
\hline Item 25: More impatient/irritable & $218(51.90)$ & $123(50.83)$ & $95(53.37)$ \\
\hline Item 26: Exausting/irritating for others & $168(40.00)$ & $101(41.74)$ & $67(37.64)$ \\
\hline Item 27: Get into more quarrels & $102(24.29)$ & $68(28.10)$ & $34(19.10)$ \\
\hline
\end{tabular}


(Table 2) contd....

\begin{tabular}{|c|c|c|c|}
\hline & $\begin{array}{c}\text { Total Sample } \\
\mathbf{N = 4 2 0}\end{array}$ & $\begin{array}{c}\text { Hypomanic Group } \\
\text { N=242 }\end{array}$ & $\begin{array}{c}\text { Non-Hypomanic Group } \\
\text { N=178 }\end{array}$ \\
\hline \hline Item 28: More optimistic & $257(61.19)$ & $197(81.40)$ & $60(33.71)$ \\
\hline Item 29: Drink more coffee & $141(33.57)$ & $102(42.15)$ & $39(21.91)$ \\
\hline Item 30: Smoke more cigarettes & $101(24.05)$ & $63(26.03)$ & $38(21.35)$ \\
\hline Item 31: Drink more alcohol & $55(13.10)$ & $42(17.36)$ & $13(7.30)$ \\
\hline Item 32: Take more drugs & $93(22.14)$ & $48(19.83)$ & $45(25.28)$ \\
\hline
\end{tabular}

and $17.32 \pm 24.56$ vs. $9.24 \pm 10.50$ in the entire life $(\mathrm{p}=0.09$ and $\mathrm{p}=0.10$, respectively).

\section{DISCUSSION}

This is the first study conducted in Italy clearly showing that a large proportion $(57.40 \%)$ of treatment-resistant MDD patients had a positive history of previous hypomanic episodes, as determined by the HCL-32. Compared with patients who did not have hypomania, those patients identified as having hypomanic features on the basis of the HCL-32 screening instrument had higher scores for both the "active/elated hypomania" and "irritable/risk-taking hypomania" subscales. Moreover, patients who were positive for hypomanic features according to the HCL-32 were younger, had more previous depressive episodes and had higher frequency of concomitant diseases.

The proportion of positive hypomanic patients in this study is higher than that reported in the aforementioned Polish study, in which the rate of treatment-resistant MDD patients with positive HCL-32 screening for hypomania was $43.9 \%$ [12]. One explanation for this difference could be the higher cut-off used in the Polish study ( $\geq 14$ positive answers) compared to our investigation ( $\geq 12$ positive answers). Of note, our cut-off was chosen in accordance with the findings of a validation study conducted in an Italian setting [18]. As a consequence, in our study about $10 \%$ more subjects were classified as positive for hypomania, their total score being between 12 and 13 . However, the mean total HCL-32 score in our study (12.95) was slightly higher than that of the Polish cohort [12], suggesting some differences related to different settings and inclusion criteria.

Recent studies have raised some doubts about the accuracy of screening instruments in detecting bipolar disorders; in particular, the MDQ was shown have low sensitivity as a screening tool in US clinical settings [20]. Screening instruments with inadequate sensitivity, particularly in patients with bipolar type II disorders, have serious implications for the detection of these diseases [21]. The sensitivity is a key factor that depends on the frequency of false negatives and is, therefore, considered to be a critical element in all research on screening and particularly in case finding due to the possibility of classifying incorrectly as positive personality disorders [22] or disorders related to stress [23]. However, our research was designed using information from a preliminary validation of the HCL-32 performed in a clinical setting in Italy [18]. Based on this previous study, we chose the cut-off of 12 to increase the sensitivity of the instrument, which was excellent $(0.85)$, while maintaining good specificity $(0.61)[18]$. At the same cut-off was also found that the performance of the HCL-32 specifically for screening for bipolar II disorders was good (sensitivity 0.80 ; specificity 0.54) [18]. The accuracy of the HCL-32 in identifying bipolar disorders according to DSM-IV criteria was determined using the SCID-IV interview, conducted by clinicians, as the gold standard [24]. Our results were similar to those found in another multicentre study in China (sensitivity 0.86 , specificity 0.69 ) [25]. The high-quality performance of the screening tool and the integrity of our results were also indirectly confirmed by the profile of demographic and clinical factors associated with hypomania. Indeed, the factors associated with being positive for this status that is more frequently related in the literature [12] to bipolar disorder than to MDD were: younger age at symptom onset, higher number of previous depressive episodes worsening course of disease and higher frequency of concomitant conditions.

In our study, more patients than expected were found to have previous hypomanic features. However, in the BRIDGE study conducted in Germany [26] that included patients with a major depressive episode, a similar proportion of bipolar patients $(58.7 \%)$ was found using the HCL-32. When DSM-IV criteria were used, the percentage of bipolar patients identified fell to only $11.6 \%$. There was a lesser difference (40.6\%) when the Bipolarity Specified Algorithm was used; this expands the DSM-IV criteria to patients with bipolar spectrum disorders. It is, therefore, possible that the large number of positive patients found in our study may be partially due to the wide range of sub-threshold bipolarity, as also described in the Chinese study [27]. Based on these data, we can tentatively hypothesize that the spectrum of bipolarity [28], including sub-threshold bipolar symptoms, could have a role in the management of treatment-resistant MDD.

Finally, the two sub-scales "active/elated hypomania" and "risk-taking/irritable hypomania" were able to detect those patients positive at the HCL-32 from among the treatment-resistant MDD patients. This could suggest a unique manic/dysphoric pattern profile in bipolar spectrum disorders, but, given the observational nature of the study, more robust information is needed to support this hypothesis.

A limit of the study is that the clinical assessment of fully diagnosed Bipolar Disorder in the sample by means of a semi-structured interview, would have allowed to separate 
actual Bipolar Disorder patients from sub-threshold bipolar ones, adding information on the ratio between misdiagnosis and actual classification limits.

In conclusion, our study confirms the relevance of undiagnosed and therefore inadequately treated bipolarity in in depression with drug resistance diagnosed as being unipolar. Early identification of hypomanic symptoms may have a strategic role in the management of this disease.

\section{CONFLICT OF INTEREST}

The authors confirm that this article content has no conflicts of interest.

\section{ACKNOWLEDGEMENTS}

The IMPROVE study was sponsored and funded by AstraZeneca. OPIS S.r.1. was in charge of data management and statistics. The authors thank OPIS S.r.l for medical writing support.

\section{REFERENCES}

[1] Compton WM, Conway KP, Stinson FS, Grant BF. Changes in the prevalence of major depression and comorbid substance use disorders in the United States between 1991-1992 and 2001-2002. Am J Psychiatr 2006; 163: 2141-7.

[2] Alonso J, Angermeyer MC, Bernert S, et al. ESEMeD/MHEDEA 2000 Investigators, European Study of the Epidemiology of Mental Disorders (ESEMeD) Project. Disability and quality of life impact of mental disorders in Europe: results from the European Study of the Epidemiology of Mental Disorders (ESEMeD) project. Acta Psychiatr Scand Suppl 2004; 420: 38-46.

[3] Olchanski N, McInnis Myers M, Halseth M, et al. The economic burden of treatment-resistant depression. Clin Ther 2013; 35: 512-22.

[4] Carta MG, Aguglia E, Bocchetta A, et al. The use of antidepressant drugs and the lifetime prevalence of major depressive disorders in Italy. Clin Pract Epidemiol Ment Health 2010; 6: 94-100

[5] Balestrieri M, Carta MG, Leonetti S, Sebastiani G, Starace F, Bellantuono C. Recognition of depression and appropriateness of antidepressant treatment in Italian primary care. Soc Psychiatry Psychiatr Epidemiol 2004; 39: 171-6.

[6] Greenberg PE, Kessler RC, Birnbaum HG, et al. The economic burden of depression in the United States: how did it change between 1990 and 2000? J Clin Psychiatr 2003; 64: 1465-75.

[7] Murray CJ, Vos T, Lozano R, et al. Disability-adjusted life years (DALYs) for 291 diseases and injuries in 21 regions, 1990-2010: a systematic analysis for the Global Burden of Disease Study 2010. Lancet 2012; 380(9859): 2197-223.

[8] Warden D, Rush AJ, Trivedi MH, et al. The STAR*D Project results: a comprehensive review of findings. Curr Psychiatry Rep 2007; 9: 449-59.

[9] Halpern JK, Glassman AH. Adequate tricyclic treatment: defining the tricyclic non responder. In: Roose SP, Glassman AH, Eds. Treatment strategies for refractory depression. Washington, DC: American Psychiatric Press 1990; pp. 11-32.

[10] Roose SP. Methodological issues in the diagnosis, treatment and study of refractory depression. In: Roose SP, Glassman AH, Eds.
Treatment strategies for refractory depression. Washington, DC: American Psychiatric Press 1990; pp. 3-9.

[11] Thase ME, Rush AJ. Treatment-resistant depression. In: Blooms FE, Kupfer DJ. Eds. Psychopharmacology: The Fourth Generation of Progress. NY: Raven Press 1995; pp. 1081-97.

[12] Dudek D, Rybakowski JK, Siwek M, et al. Risk factors of treatment resistance in major depression: association with bipolarity. J Affect Disord 2010; 126: 268-71.

[13] Hirschfeld RM, Calabrese JR, Weissman MM, et al. Screening for bipolar disorder in the community. J Clin Psychiatr 2003; 64: 53-9.

[14] Hirschfeld RM, Lewis L, Vornik LA. Perceptions and impact of bipolar disorder. How far have we really come? Results of the national depressive and manic-depressive association 2000 survey of individuals with bipolar disorder. J Clin Psychiatr 2003; 64: 161-74.

[15] Carta MG, Angst J. Epidemiological and clinical aspects of bipolar disorders: controversies or a common need to redefine the aims and methodological aspects of surveys. Clin Pract Epidemol Ment Health $2005 ; 1: 4$.

[16] Fountoulakis KN, Kasper S, Andreassen O, et al. Efficacy of pharmacotherapy in bipolar disorder: a report by the WPA section on pharmacopsychiatry. Eur Arch Psychiatr Clin Neurosci 2012; 262 (Suppl 1): 1-48.

[17] Ei-Mallakh RS, Karippot A. Antidepressant-associated chronic irritable dysphoria (acid) in bipolar disorder: a case series. J Affect Disord 2005; 84: 267-72.

[18] Carta MG, Hardoy MC, Cadeddu M, et al. The accuracy of the Italian version of the Hypomania Checklist (HCL-32) for the screening of bipolar disorders and comparison with the Mood Disorder Questionnaire (MDQ) in a clinical sample. Clin Pract Epidemiol Ment Health 2006; 2: 2.

[19] Angst J, Meyer TD, Adolfsson R, et al. Hypomania: a transcultural perspective. World Psychiatr 2010; 9(1): 41-9.

[20] Zimmerman M, Galione JN, Ruggero CJ, et al. Performance of the mood disorders questionnaire in a psychiatric outpatient setting. Bipolar Disord 2009; 11: 759-65.

[21] Merikangas KR, Jin R, He JP, et al. Prevalence and correlates of bipolar spectrum disorder in the world mental health survey initiative. Arch Gen Psychiatr 2011; 68: 241-51.

[22] Zimmerman M, Galione JN, Ruggero CJ, et al. Screening for bipolar disorder and finding borderline personality disorder. J Clin Psychiatr 2010; 71(9): 1212-7.

[23] Carta MG, Balestrieri M, Murru A, Hardoy MC. Adjustment Disorder: epidemiology, diagnosis and treatment. Clin Pract Epidemiol Ment Health 2009; 5: 15.

[24] First MB, Spitzer RL, Gibbon M, Williams JB. Structured clinical interview for DSM-IV Axis I Disorders Clinician Version (SCIDCV). Washington DC: American Psychiatric Press 1997.

[25] Yang HC, Xiang YT, Liu TB, et al. Hypomanic symptoms assessed by the HCL-32 in patients with major depressive disorder: a multicenter trial across China. J Affect Disord 2012; 143: 203-37.

[26] Bschor T, Angst J, Azorin JM, et al. Are bipolar disorders underdiagnosed in patients with depressive episodes? Results of the multicenter BRIDGE screening study in Germany. J Affect Disord 2012; 142: $45-52$.

[27] Hu C, Xiang YT, Ungvari GS, et al. Undiagnosed bipolar disorder in patients treated for major depression in China. J Affect Disord 2012; 140: 181-6.

[28] Akiskal HS, Akiskal KK, Lancrenon S, et al. Validating the bipolar spectrum in the French National EPIDEP Study: overview of the phenomenology and relative prevalence of its clinical prototypes. J Affect Disord 2006; 96: 197-205.

(C) Francesca et al.; Licensee Bentham Open.

This is an open access article licensed under the terms of the Creative Commons Attribution Non-Commercial License (http://creativecommons.org/licenses/by-nc/3.0/) which permits unrestricted, non-commercial use, distribution and reproduction in any medium, provided the work is properly cited. 